\title{
A METHOD FOR THE SEPARATION OF RUTHENIUM FROM PLATINUM, PALLADIUM, RHODIUM, AND IRIDIUM
}

\author{
By Raleigh Gilchrist
}

\section{ABSTRACT}

A procedure for the separation and gravimetric determination of ruthenium is described. The method of separation differs essentially from existing methods in that the ruthenium is distilled from a solution of its sulphate in diluted sulphuric acid containing sodium bromate. A very suitable reagent for the quantitative absorption of the distilled tetroxide was found to be diluted hydrochloric acid saturated with sulphur dioxide. The recovery of ruthenium is accomplished by precipitating the hydrated oxide from a boiling solution at pH6, after sulphite compounds have been decomposed by treatment with hydrochloric acid. The hydrated oxide is ignited in the air to an anhydrous oxide which is then reduced to metal under hydrogen.

\section{CONTENTS}

Page 283

I. Introduction

II. Distillation of ruthenium from acid solutions containing sodium bromate

III. Method of analysis recommended

1. Distilling apparatus.

2. Preparation of the solution

3. Separation of ruthenium

4. Recovery and determination of ruthenium

\section{INTRODUCTION}

In a previous paper ${ }^{1}$ from this laboratory, a method was described for the quantitative precipitation of ruthenium as a hydrated oxide from chloride solution and for its determination as metal. The purpose of this paper is to present a method for the separation of ruthenium from the other platinum metals, and to combine this method with that mentioned above.

Ruthenium and osmium, through their ability to exist as volatile tetroxides, can be removed from solution by distillation. Advantage has been taken of this property in every scheme of analysis which has been proposed. Sufficient differences exist in the conditions affecting the formation of these two volatile compounds so that they can be separated from each other, or they can be distilled together from the same solution. The customary procedure has been first to distill a

1 R. Gilchrist, B. S. Jour. Research, vol. 3, p. 993, 1929. 
solution strongly acid with nitric acid, thereby eliminating osmium, and then to make the solution strongly alkaline, saturate it with chlorine, and distill again to remove ruthenium. In one method, at least, that of Leidié ${ }^{2}$, the two tetroxides are distilled simultaneously from an alkaline hypochlorite solution and subsequently separated from each other.

In a recent study of the separation and determination of osmium, ${ }^{3}$ it was found that no ruthenium was volatilised from solutions containing as much as 40 percent of nitric acid by volume. During the distillation of osmium from nitric-acid solution, the other platinum metals remain as soluble compounds in the distilling flask.

During the subsequent distillation of ruthenium from an alkaline hypochlorite solution, on the other hand, a precipitate consisting of the hydrated oxides of iridium, rhodium and palladium separates as the hot alkaline solution becomes saturated with chlorine. It has been repeatedly observed that such a precipitate carries with it some ruthenium. It then becomes necessary to cool the solution, to add fresh alkali, and to repeat the saturation with chlorine. Such treatment must be repeated a number of times without certainty of complete removal of the ruthenium. A procedure of this kind becomes extremely tedious and furthermore causes the introduction of a great quantity of allali salts which interfere with subsequent analytical operations. From a solution containing $0.1670 \mathrm{~g}$ of ruthenium in the presence of $1.4 \mathrm{~g}$ of iridium, only $0.1623 \mathrm{~g}$ of ruthenium was recovered, although the treatment with additional alkali and the saturation with chlorine was repeated six times and no more ruthenium appeared to distill. This result confirms previous observations on the incomplete elimination of ruthenium by this method in refining operations. On the contrary, in three experiments in which $0.1901 \mathrm{~g}, 0.1658 \mathrm{~g}$, and $0.1468 \mathrm{~g}$ of ruthenium were taken and iridium was absent, $0.1900 \mathrm{~g}, 0.1659 \mathrm{~g}$, and $0.1468 \mathrm{~g}$ of ruthenium were recovered, respectively. Distillation was continued for $1 \frac{1}{2}$ hours after saturating the cold solutions with chlorine, although the ruthenium appeared to be practically all removed in the first 15 minutes after boiling began. Since iridium invariably accompanies ruthenium in platiniferous materials, there appears to be little hope that this method can be made the basis of a simple, accurate means for isolating ruthenium analytically.

In the experiments just mentioned, the ruthenium tetroxide was caught in diluted hydrochloric acid $(1+1)^{4}$ contained in four flasks, the last one with a little alcohol also. The ruthenium was distributed throughout the four flasks, but only a small amount was present in the last one.

Another method of separating ruthenium, which was proposed only a few years ago in a scheme of qualitative analysis, consists in distilling ruthenium tetroxide from perchloric acid. ${ }^{5}$ Attempts to use this procedure were made in this laboratory ${ }^{6}$ but it was found

2 E. Leidié, Compt. rend., vol. 131, p. 888, 1900.

3 Gilchrist, B. S. Jour. Research, vol. 6, p. $421,1931$.

4 Throughout this paper, whenever acids are mentioned, hydrochloric acid will mean the concentrated acid of specific gravity 1.18; sulphuric acid, the concentrated acid of specific gravity 1.84; nitric acid, the concentrated acid of specific gravity 1.42; and hydrobromic acid, the 40 percent acid of commerce. Diluted acids will be designated as follows: For example, diluted hydrochloric acid (1+99) will mean 1 volume of the concentrated acid of specific gravity 1.18 diluted with 99 volumes of water.

5 A. A. Noyes and W. C. Bray, Qualitative Analysis for the Rare Elements. The MacMillan Co., 1927.

6 Unpublished work by H. A. Buchheit. 
that here again iridium dioxide precipitated in the distilling flask when the solution was heated until vapors of perchloric acid were evolved and that the separation of ruthenium was not complete.

H. E. Holbrook, ${ }^{7}$ of the H. A. Wilson Co., suggested a method in which precipitation of iridium dioxide is avoided by distilling from a solution containing sulphuric acid. In this method, the product formed in an alkali-nitrate fusion of the ruthenium material is treated with water containing sulphuric acid and placed in a distilling apparatus together with sodium chlorate and sodium chloride. The resulting solution is heated to boiling and the ruthenium eliminated as the tetroxide. In attempting to use this method for distilling ruthenium tetroxide from a solution of ammonium chlororuthenate in diluted sulphuric acid, a deposit of ruthenium dioxide was frequently obtained on the inner walls of the distilling flask and of the delivery tube leading to the first absorbing flask. The cause of this unexpected behavior did not become apparent until somewhat later when it was finally traced to the presence of hydrochloric acid which reduced the hot tetroxide vapors.

Further attempts to use sodium chlorate as an oxidizing reagent were abandoned, when, in the meantime, it was found that sodium bromate was a much more suitable reagent.

\section{DISTILLATION OF RUTHENIUM FROM ACID SOLUTIONS CONTAINING SODIUM BROMATE}

It was observed that ruthenium tetroxide is produced when a neutral or acid solution containing ruthenium is treated with sodium bromate or with sodium chlorate. In acid solution, the bromate ion and the chlorate ion are comparatively stable toward sulphuric acid or nitric acid but are readily decomposed by either hydrochloric or hydrobromic acid.

The problem at hand was to establish conditions suitable for the rapid and complete elimination of ruthenium and to prevent the precipitation of the other platinum metals during the operation. A number of preliminary experiments were made in which such factors as the following were varied: The nature and quantity of the acid added to prevent precipitation in the distilling flask; the nature and quantity of the reagent solution added to oxidize the ruthenium to the tetroxide; the temperature at which the distillation should be conducted; the preparation of the ruthenium solution previous to distillation; the length of time of distillation; the effect of the presence of-other platinum metals.

The apparatus used was the same as that described in a previous paper ${ }^{8}$ and which is shown in figure 1 in the section on recommended procedure. The solution used to absorb the liberated tetroxide consisted of diluted hydrochloric acid $(1+1)$, freshly saturated with sulphur dioxide. The initial volume of the ruthenium solution in the distilling flask was $100 \mathrm{ml}$ in each instance. The volume of the solution at the end of the distilling operation was usually between 200 and $300 \mathrm{ml}$, owing to the addition of the oxidizing reagent and of water necessary to keep the liquid column in the thistle tube free from dissolved tetroxide.

It was found that sulphuric acid was the most suitable of the commonly available acids for use in the distilling flask and that $10 \mathrm{ml}$ of

7 Private communication.

See footnote 3, p. 284. 
it was sufficient, in the volume used, to prevent the precipitation of iridium dioxide. Hydrochloric acid and hydrobromic acid were not only unsuitable but objectionable. When present in even small quantities, they caused decomposition of the bromate ion and the evolution of large amounts of bromine. Furthermore, their presence caused a film of ruthenium dioxide to be formed on the walls of the apparatus unless care was taken to control the temperature of distillation. No way was found by which this film could be readily dissolved and as a consequence its formation had to be avoided.

It was found possible to distill ruthenium from a nitric-acid solution so that this operation could be conducted immediately after the elimination of osmium by simply adding sodium bromate. In analysis no. 516 (table 1), the ruthenium was distilled from diluted nitric acid $(1+9)$ to which it was found necessary to add $5 \mathrm{ml}$ of nitric acid as

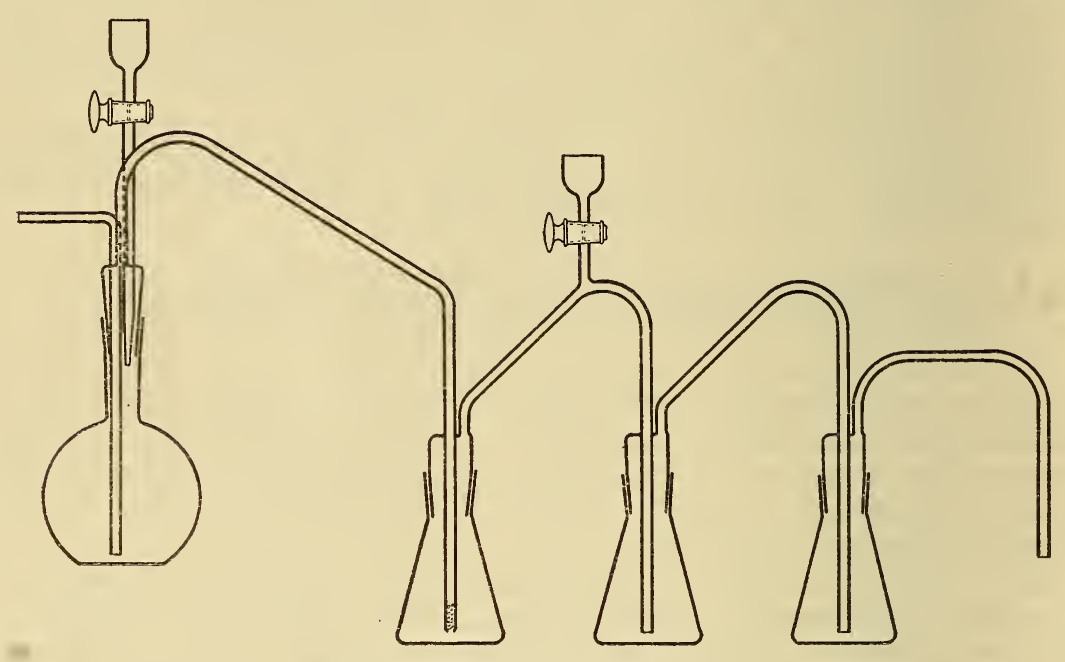

Figure 1.-Distilling flask with train.

the distillation progressed, in order to prevent hydrolytic precipitation of the iridium. While this procedure can be used, it has the disadvantage that distillation of nitric acid causes a rather large quantity of sulphuric acid to be formed by reaction in the absorbing solution, the presence of which was found to interfere in the hydrolytic precipitation of hydrated ruthenium oxide unless the evaporated absorbent solution was first heated until vapors of sulphuric acid ${ }^{9}$ were evolved.

No advantage appeared to be gained by adding the bromate either continuously or at intervals, nor did the addition of bromide appear to be useful or desirable. In analyses nos. 505 and 506, a mixed solution of sodium bromate and sodium bromide was added intermittently, while in analysis no. 507 this mixture was dripped in continuously. In all of the experiments which follow analysis no. 516 in numerical order, only bromate was used, the entire amount of which, $100 \mathrm{ml}$ of a 10 percent solution, was added at the start of the distillation. In the other experiments reported in table 1 , the bromate solution was added at intervals and varied in total amount from 40 to $100 \mathrm{ml}$.

That no significant loss of ruthenium occurs when such a solution is heated until vapors of sulphuric acid are liberated is shown by the result obtained in analysis no. 516 as well as by those given in table 2 , which confirm the observation reported in the paper on the separation of osmium. (See footnote 3, p. 284.) 
It was observed that the nature of the ruthenium compound taken as the sample had some effect on the ease with which the tetroxide was formed. When taken as the chlororuthenate, as in analyses nos. 502 to 509 , a considerable length of time was necessary to remove the last trace of ruthenium. In marked contrast to the relatively slow formation of tetroxide from the chlororuthenate was the rapid formation of ruthenium tetroxide from ruthenium sulphate. A further advantage that is gained by distilling from a solution of ruthenium which has been heated until vapors of sulphuric acid are formed is that hydrochloric acid and hydrobromic acid are absent, and consequently the entire distilling operation can be conducted at the boiling temperature without danger of the deposition of ruthenium dioxide. The minimum time required under these conditions was found to be 2 hours.

The presence of iridium, palladium, rhodium, and platinum in solutions which had not been evaporated with sulphuric acid was found to have no effect on the separation of ruthenium, provided a sufficient quantity of sulphuric acid, $10 \mathrm{ml}$, had been added. In solutions which had been heated until vapors of sulphuric acid were given off, ruthenium, iridium, rhodium, and palladium formed soluble sulphates, while most of the platinum separated as metal. The metallic platinum thus precipitated, however, was found not to affect the elimination of ruthenium.

The results of the preliminary experiments are given in table 1. The amount of ruthenium in the residual solutions was determined colorimetrically by comparison with solutions of known ruthenium content. For this purpose, the solutions were first saturated with sulphur dioxide and treated with a few crystals of thiourea. On standing for 24 hours, a greenish or bluish color developed, depending upon the amount of ruthenium present.

TABLE 1.-Results of the preliminary experiments on the distillation of ruthenium tetroxide

\begin{tabular}{|c|c|c|c|c|c|c|c|c|}
\hline $\begin{array}{l}\text { Analy- } \\
\text { sis } \\
\text { no. }\end{array}$ & $\mid \begin{array}{c}\text { Ruthe- } \\
\text { nium } \\
\text { salt } \\
\text { taken }\end{array}$ & $\mid \begin{array}{l}\text { Ruthe- } \\
\text { nium } \\
\text { pres- } \\
\text { ent } 1\end{array}$ & $\begin{array}{c}\text { Ruthe- } \\
\text { nium } \\
\text { recov- } \\
\text { ered }\end{array}$ & Error & $\begin{array}{l}\text { Test for ruthe- } \\
\text { nium in residual } \\
\text { solution }\end{array}$ & $\begin{array}{c}\text { Total } \\
\text { time } \\
\text { of dis- } \\
\text { tilla- } \\
\text { tion }\end{array}$ & $\begin{array}{c}\text { Other } \\
\text { platinum } \\
\text { metals } \\
\text { present }\end{array}$ & Remarks \\
\hline & $0 . \stackrel{g}{4} 772$ & 0.1415 & 0.1415 & 0. $\stackrel{g}{0}$ & Less than $0.1 \mathrm{mg}$ & $\begin{array}{r}h r \\
9\end{array}$ & $g$ & \\
\hline & $\begin{array}{r}.4410 \\
.4727\end{array}$ & $\begin{array}{r}.1308 \\
1402\end{array}$ & $\begin{array}{r}.1310 \\
.1398\end{array}$ & +.0002 & Colorless & $\begin{array}{l}4 \\
31\end{array}$ & & Stonned at ond of $31 / \mathrm{hr}$ \\
\hline 506 & .4216 & .1250 & .1237 & -.0013 & slightly greater & 4 & & Stopped at end of $4 \mathrm{hr}$. \\
\hline $\begin{array}{l}507 \ldots \\
511 \ldots \\
512- \\
516 \\
520- \\
-.\end{array}$ & $\begin{array}{l}.3977 \\
.3513 \\
.3524 \\
.4166 \\
.3689\end{array}$ & $\begin{array}{l}.1180 \\
.1042 \\
.1045 \\
.1236 \\
.1094\end{array}$ & $\begin{array}{l}.1180 \\
.1043 \\
.1044 \\
.1237 \\
.1093\end{array}$ & $\begin{array}{r}.0000 \\
+.0001 \\
.0001 \\
+.0001 \\
-.0001\end{array}$ & $\begin{array}{l}\text { Less than } 0.1 \mathrm{mg} \\
\text { Colorless.. } \\
0.1 \mathrm{mg} \\
\text { Colorless. } \\
0.1 \mathrm{mg}\end{array}$ & $\begin{array}{c}7 \\
4 \\
3 \\
31 / 2 \\
10^{1 / 2}\end{array}$ & & Distilled from nitric acid. \\
\hline 509. & .3676 & .1090 & .1091 & +.0001 & Not made-.. & $11 \frac{1}{2}$ & $0.093 \mathrm{Ir}$ & No $\mathrm{Ru}$ appeared to distill \\
\hline 510. & .4109 & .1219 & .1222 & +.0003 & do. & $51 / 2$ & $\begin{array}{l}.015 \mathrm{Ir} \\
.020 \mathrm{Rh} \\
.010 \mathrm{Pd} \\
.050 \mathrm{Pt}\end{array}$ & \\
\hline 621 & .5274 & .1564 & .1565 & +.0001 & -. do & 7 & $.1426 \mathrm{Ir}$ & $\begin{array}{c}\text { Distilled } 31 / 2 \mathrm{hr} \text { at } 70 \mathrm{C}, 31 / 2 \\
\text { hr at boiling temperature. }\end{array}$ \\
\hline 623-602_ & .5247 & .1556 & .1556 & .0000 & -..-do_ & 7 & $.1605 \mathrm{Ir}$ & $\begin{array}{l}\text { Distilled } 4 \mathrm{hr} \text { at } 70 \mathrm{C}, 3 \mathrm{hr} \text { at } \\
\text { boiling temperature. }\end{array}$ \\
\hline
\end{tabular}

1 Calculated on the basis of an experimentally determined ruthenium content of 29.66 percent.

NoтE.-In analyses nos. 621-601 and 623-602, the iridium which had been added was recovered by hydrolytic precipitation at $\mathrm{pH} 6$ and determined as metal. The quantities of iridium recovered were $0.1427 \mathrm{~g}$ and $0.1603 \mathrm{~g}$, respectively. The slight loss in the recovery in analysis no. 623-602 was caused by a faint mirror of iridium dioxide which could not be removed from the beaker in which the precipitation was made. 
The results of the experiments in which ruthenium was distilled from solutions which had first been heated until copious vapors of sulphuric acid were evolved, according to the procedure finally adopted, are given in table 2. In these experiments, $100 \mathrm{ml}$ of a 10 percent solution of sodium bromate was added to the solution in the distilling flask, the initial volume of which was $100 \mathrm{ml}$. In analyses nos. 625 and 626 , the solutions were heated to boiling for 1 hour after most of the ruthenium had been eliminated at a somewhat lower temperature. This period of boiling proved to be insufficient and was increased to $1 \frac{1}{2}$ hours in analyses nos. 627,628 , and 629 . It was later found that if the entire distillation was made at the boiling temperature a period of 2 hours is necessary and sufficient.

TABLE 2.-Results of the determination of ruthenium when distilled from sulphate solution

\begin{tabular}{|c|c|c|c|c|c|c|c|c|}
\hline $\begin{array}{l}\text { Analy- } \\
\text { sis no. }\end{array}$ & $\begin{array}{l}\text { Ruthe- } \\
\text { nium } \\
\text { salt } \\
\text { taken }\end{array}$ & $\begin{array}{l}\text { Ruthe- } \\
\text { nium } \\
\text { pres- } \\
\text { ent } 1\end{array}$ & $\begin{array}{l}\text { Ruthe- } \\
\text { nium } \\
\text { recov- } \\
\text { ered }\end{array}$ & Error & $\begin{array}{l}\text { Test for ruthe- } \\
\text { nium in resid- } \\
\text { ual solution }\end{array}$ & $\begin{array}{c}\text { Total } \\
\text { time } \\
\text { of dis- } \\
\text { tilla- } \\
\text { tion }\end{array}$ & $\begin{array}{l}\text { Other } \\
\text { platinum } \\
\text { metals } \\
\text { present }\end{array}$ & Remarks \\
\hline 625 & $\stackrel{g}{g}$ & $\stackrel{g}{0.1446}$ & $\stackrel{g}{0.1445}$ & -0.0001 & Less than $0.1 \mathrm{mg}$ - & $\begin{array}{c}h r \\
21 / 2\end{array}$ & $g$ & \multirow{3}{*}{$\begin{array}{l}\text { Distilled at boiling tempera- } \\
\text { ture for } 1 \mathrm{hr} \text {. } \\
\text { Do. } \\
\text { Distilled at boiling tempera- } \\
\text { ture for } 1 \frac{1}{2} \mathrm{hr} \text {. } \\
\text { Do. } \\
\text { Do. }\end{array}$} \\
\hline $\begin{array}{l}626-\cdots- \\
627--\end{array}$ & $\begin{array}{l}.4412 \\
.3844\end{array}$ & $\begin{array}{l}.1309 \\
.1140\end{array}$ & $\begin{array}{l}.1307 \\
.1140\end{array}$ & $\begin{array}{r}-.0002 \\
.0000\end{array}$ & $\begin{array}{l}0.2-0.3 \mathrm{mg} \\
\text { Colorless } \\
-\end{array}$ & $\begin{array}{l}3 \\
31 / 2\end{array}$ & & \\
\hline $\begin{array}{l}628 \\
629\end{array}$ & $\begin{array}{l}.4192 \\
.3889\end{array}$ & $\begin{array}{l}.1243 \\
.1153\end{array}$ & $\begin{array}{l}.1244 \\
.1152\end{array}$ & $\begin{array}{l}+.0001 \\
-.0001\end{array}$ & Not made. & $\begin{array}{l}31 / 2 \\
3\end{array}$ & $\begin{array}{l}0.2125 \mathrm{Ir} \\
.1955 \mathrm{Ir} \\
.0076 \mathrm{Rh} \\
.1084 \mathrm{Pd} \\
.2739 \mathrm{Pt}\end{array}$ & \\
\hline
\end{tabular}

1 Calculated on the basis of an experimentally determined ruthenium content of 29.66 percent.

\section{METHOD OF ANALYSIS RECOMMENDED}

The following procedure is designed to separate ruthenium as the volatile tetroxide from a solution containing the platinum group of metals, with the exception of osmium which must be absent; to recover the evolved tetroxide by absorption in diluted hydrochloric acid $(1+1)$ which has been freshly saturated with sulphur dioxide; to precipitate the ruthenium as a hydrated oxide from the absorbent solution; and to obtain the ruthenium as metal.

\section{DISTILLING APPARATUS}

The distilling apparatus is shown in figure 1. It consists of three main parts, namely, a $700 \mathrm{ml}$ distilling flask, a set of three $300 \mathrm{ml}$ absorbing flasks, and a train of inlet and delivery tubes which are sealed into one piece. The thistle tube closed by a stopcock, placed between the first and second absorbing flasks, serves to replenish the absorbing solution with sulphurous acid and also to rinse the tube connecting the two flasks at the end of the distillation. The entire apparatus is constructed of pyrex glass. The joints must be very carefully ground, since no organic lubricant can be used except on the stopcock of the thistle tube which leads into the distilling flask. The joints are therefore sealed with a film of water only. The stem of the thistle tube which leads into the distilling flask should have a diameter which will allow a column of water to be held in it. It is extremely important that this tube be flushed occasionally in order to remove any tetroxide which diffuses into it. 


\section{PREPARATION OF THE SOLUTION}

Evaporate to dryness on the steam bath the solution which remains in the distilling flask after the elimination of osmium. Add 5 to $10 \mathrm{ml}$ of hydrochloric acid and again evaporate the solution. Repeat the evaporation with hydrochloric acid until oxides of nitrogen are no longer evolved. This precaution is taken to avoid the danger of a slight loss of ruthenium if the nitric-acid solution were simply evaporated and heated until vapors of sulphuric acid were formed. Dilute the chloride solution, add $10 \mathrm{ml}$ of sulphuric acid, and evaporate carefully until heavy vapors of sulphuric acid are evolved. Transfer the solution and any metallic platinum which may have separated to the distilling flask and dilute it to about $100 \mathrm{ml}$ with water.

\section{SEPARATION OF RUTHENIUM}

Place $150 \mathrm{ml}$ of diluted hydrochloric acid $(1+1)$, freshly saturated with sulphur dioxide, in the first receiving flask and $50 \mathrm{ml}$ of the same solution in each of the other two receiving flasks. Add $100 \mathrm{ml}$ of a 10 percent solution of sodium bromate through the thistle tube to the distilling flask. Pass a gentle current of air through the apparatus and heat the solution in the distilling flask to boiling. Distill at this temperature for 2 hours. Add a portion of freshly prepared sulphurous acid through the other thistle tube occasionally in order to replenish the absorbing solution with sulphur dioxide. At the end of the distillation, flush the delivery tube between the first and second absorbing flasks with sulphurous acid.

\section{RECOVERY AND DETERMINATION OF RUTHENIUM}

Combine the portions of the absorbing solution and evaporate to a moist residue on the steam bath. Add $10 \mathrm{ml}$ of hydrochloric acid and digest the solution for $1 / 2$ hour. Add $50 \mathrm{ml}$ of water and heat the solution to boiling in order to complete the dissolving of the somewhat difficultly soluble ruthenium compound. When the ruthenium compound is completely dissolved, filter the solution and wash the filter with diluted hydrochloric acid $(1+99)$. The solution is filtered to insure the elimination of a small amount of silica which may be present. Dilute the ruthenium solution to $200 \mathrm{ml}$, heat it to boiling, and add a filtered 10 percent solution of sodium bicarbonate until a precipitate begins to form. Add the bicarbonate solution dropwise until the acidity of the solution reaches a value of $\mathrm{pH} 6$ as indicated by the change in color from yellow to blue of brom cresol purple indicator present in the solution. Boil the solution for 5 to 6 minutes and filter it.

Wipe the inner walls of the beaker and also the glass rod with a small piece of ashless filter paper. Thoroughly wash the filter and precipitate with a hot 1 percent solution of ammonium sulphate. Finally wash them 3 or 4 times with a cold 2.5 percent solution of ammonium sulphate.

Place the filter and precipitate in a porcelain crucible, dry them, and char the filter slowly. The dried filter will usually char completely when once it begins to smoke. This operation should be done carefully in order to prevent loss of ruthenium by deflagration. Ignite the residue strongly in air and then in hydrogen. Cool the 
resulting metal in hydrogen and leach it well with hot water. This is done to insure complete removal of soluble salts. It is well to leach the residue in the crucible first and then to transfer it to a filter. Ignite the filter and metal in air and in hydrogen. Cool the residue in hydrogen and weigh it as metallic ruthenium.

The method which has just been given for the separation and determination of ruthenium is designed to follow the procedure for the separation of osmium in a general scheme for the analysis of the platinum group. The treatment of the solution which remains in the distilling flask after the separation of ruthenium will be given in a separate paper.

The writer wishes to express his appreciation of the helpful suggestions of Edward Wichers.

Washington, December 14, 1933. 